LA-UR $-90-413$

Rip:a: : i :

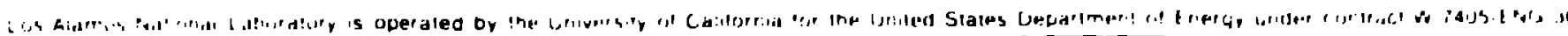

LA-UR- $-90-413$

DE90 007622

IITLE Hurmonic Ceneration Mechanisms in Short-Wavelength Free-Electron Lascers

AUTHOR(S)

Mark J. Schmitt

SUamitite to Proceedings of the Frec Electron lasers and Applications Conference helit as purt of the OE/LASt: symposium

Los Angeles, CA

Jariuory 1519,1990

\title{
DISCLAIMER
}

This report was prepared as un accusunt of work sponssied by an agency of the Inited States Ciovernment Neither the I/nited Sitates Government nor any agency thereof, nor any of their employees, makes any warranty. express of implied, or assumes any legal liabilily ur responsihility for the accuracy, completeness, of usefulness of any information, apparalus, product, of pricess disclised. or represents that ils use would nut infringe privately uwned right, Reference lielein (1) any specific commercial producl, piccess, or service by trade name. Irademark. manulaclurer, or uherwise does noll necessurily con-litule or imply lts endorsement, recom. mendiltoun, or lavoring by the l'nited Siales fiovernment or any agency thereol I he viewa and ipinions of authors expressed herein do nol necessarily slate or reflect those of the IIniled Sitales riovernment or any agency theresl

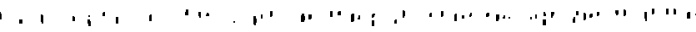

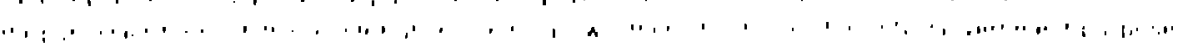

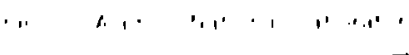

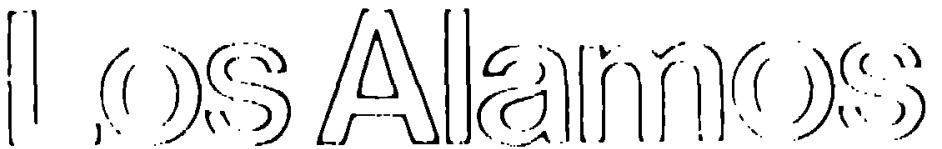

Los Alamos Natiomal Laboratesy

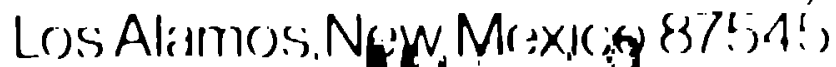


Hnemonic genciation meclanuisus in flort-wavelength frec-electron lusers

Mark J. Schmiıน

Los Alamos National Laboratory, P. O. Box 1603
MIS E531, Los Alarnos, New Mexico 875.15

\begin{abstract}
AlBSTRACT
The physical mechanisms that contribute to harmonic radiation in free-electron laser systems are examined. Mathernatical models for the spontancous and coherent-spontaneous enission in plane-polarized wigglers are given. Ilow these models are used to perform numerical simulations is diseussed. Modifications of the models to incorporale non-ideal free-electron laser effects are reviewed.
\end{abstract}

\title{
L. NTROOUC:ION
}

The radiation from relativistic electrons in free electron lasers (FELs) is coneentrated in narrow frequeney bands centered at integer multiples of the resonant frequeney. The narrow bandwidth of this radiation is caused by interference of the radiation from each of the $N$ periods of the wiggle: The electronagnetic radiation produced at lwice the resonnat frectueney (second harmonic) is a consequence of the finite transverse dimensions of the electron licam 1,: Radiation at harmonic frequencie's above the second linrnonie appears as a result of doubly-periodic osrillations in the electron's velocity inside the wiggler ${ }^{3}$. The power observed at the harmonic frequencics can vary significantly depending on the strength of the wiggler magnetic vector polential4. Additionial coupling to the harmonic frequencies can also occur when the clectron, optiral and wiggler axes are misaligned'. 'To solne degree, such misalignment will exist in any pliysical system in the form of eleetrun beam oflsets, wandering of the electron beam inside the wiggler due to field errors and bitint ron unction of the single-elect ron trajectorics.

All electron beam pissing through a wiggler will radiate epontancously fue to the random distribution of its individual electron constituents. The characteristics of this incoherent radiation can be analytically delermineel's. Alternatively, if the wiggler is long enough or some type of optieal feedback is provided, the spontancous radiation can grow into a large colicrent signal as the electrons in the bean legin to bunclı The extent of t..e bunching is criticaliy dependent on the radiation wavelength (since bunching must occur at this waveleng(h) and the statisticial cliararleristies of the electron bealn. P'roper antalysis of such a system ciun loe accomplished through numreical simulation," Hy incorporating the inhomogeneity of the clectron radiat ors, i.c., the unique three-dimensional position, velocity and ficld vectory experienced by each electron, an accurnte prediction of the fundament al and harmonic radiation output can be marle.

In the quest for coluerent shert-wavelrnglh radiation one is interested in determining the level of the harmonir colierent-sponlancouk cunission in FELLs. Planr-polarized wigglers Ir.nd thennse!lves to harmonic production owing to the non-uniform axinl component of the electrons' motion in the siuusejidal wiggher mugnetic field. 'Therefore, the following dise ussions will assume a plane-polarized wighler field configurntion. To model as many e:Trects as possible one should begin with the most general deseription of the electron

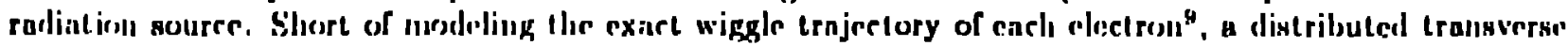

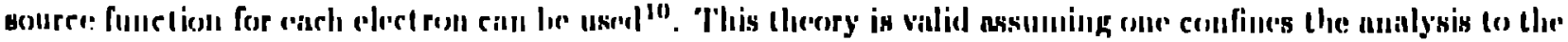

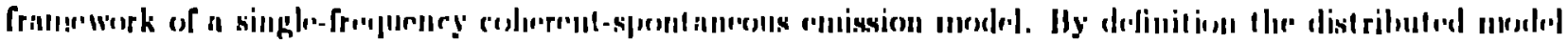

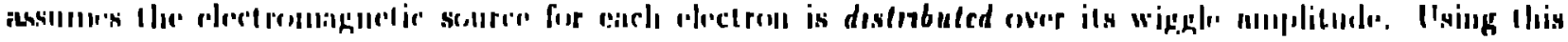

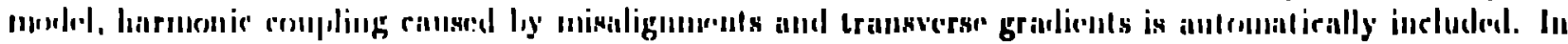

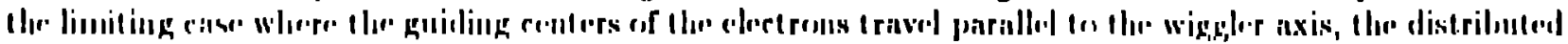

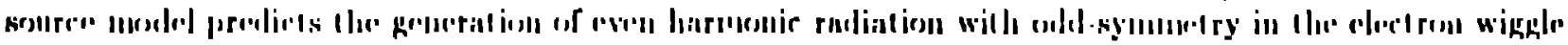


plane and odd harmonic radialion pitterns with even transverse symmetry.

In Section 2. a lorier review of the theory of spont annesus emission for typical F.L. configurations is given. The rest of the piaper is devoled to the underst inding and modeling of the viriunes effeets that comitribute to coherent-spont ancuns harmonic enission in FELLs. In Section 3. a description of the theory fer harmonie radiation from plante-poliarize-d wiggher magnetic fields cansed hy non-uniform axial s:lectron mortion, clectron density gradients, transserse electron Jrift motion, transsverse wiggher magnetic fielil gradients and harmonic Fourier components of the wiggler magnetie field is givin. The conclusions, includmg one person : view of what lies aliead in the area of FEL harmonic theory and simulation, are contai.red in Section 4.

\section{SPONTANEOLS ENISSION}

Wigglers are used r.s insertion devicra in high energy otorage rings te hoost the power levels of available incolierent electromagnetic radiation. The simplest configuration is a plane-polarized wiggler of length $L_{w}=N^{\prime} \lambda_{w}$ and peak magnctic field strength $B_{w}$, driven by an electron beam of energy rmes. The energy radiat ed by each electron of charge $q=-e$ per unit solid angle and frequency bandwidth is given by

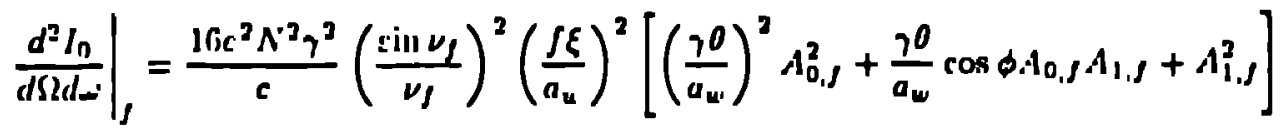

where

$$
\begin{aligned}
& A_{n, J}=(-1)^{f+a} \sum_{n=-\infty}^{\infty}(-1)^{n} J_{n}\left(\int \xi\right)\left[J_{f-3 n-a}\left(\int \sigma\right)+J_{J-3 n+a}\left(\int \sigma\right)\right] \\
& \nu_{f}=\pi . V\left[f-\frac{\lambda_{u_{1}}}{2 \gamma^{2} \lambda_{r}}\left(1+a_{u}^{2} / 2+\gamma^{2} 0^{2}\right)\right] \\
& \int \sigma=\frac{\beta\left(\int \xi\right)(\gamma \rho)}{a_{\mathrm{u}}} \cos \phi \\
& \xi=\frac{a_{u-1}^{2}}{4\left(1+a_{u}^{2} / 2+\gamma^{2} 0^{2}\right)}
\end{aligned}
$$

and

$$
a_{w}=\frac{|r| B_{u} \cdot \lambda_{w}}{2 \pi m r^{2}}
$$

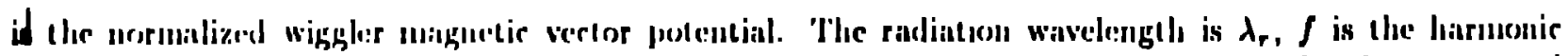

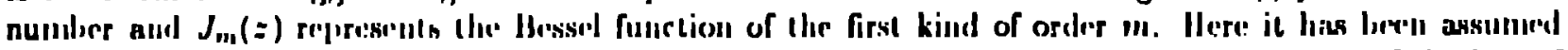

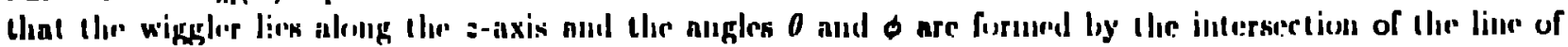
observition, cill it in, with the z-axis nnd the angle manls: hy the intersection of the projection of in onto

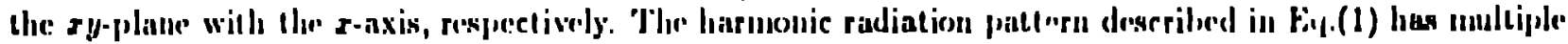

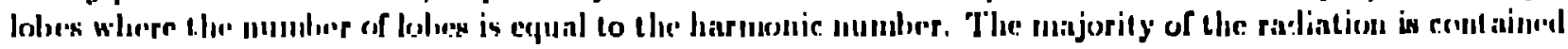
within a forwiard contre of amgle $0 \simeq 1 / \gamma$.

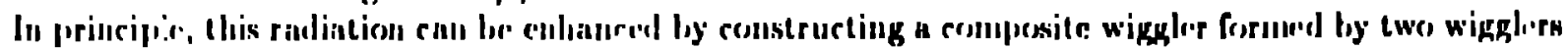

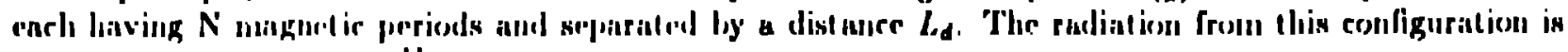
given in lerrlls of lill.(1) is"

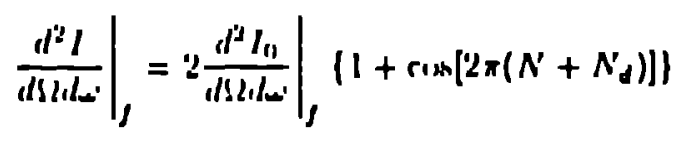

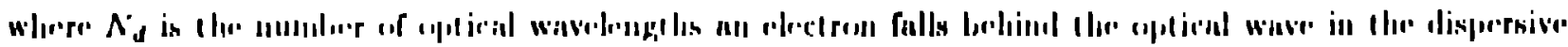

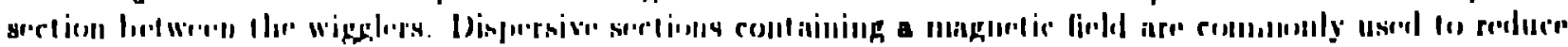

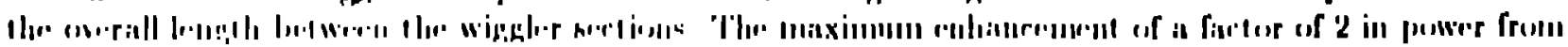

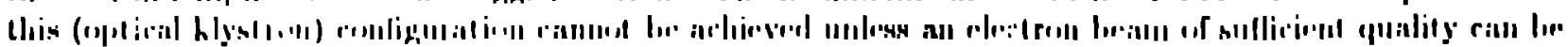




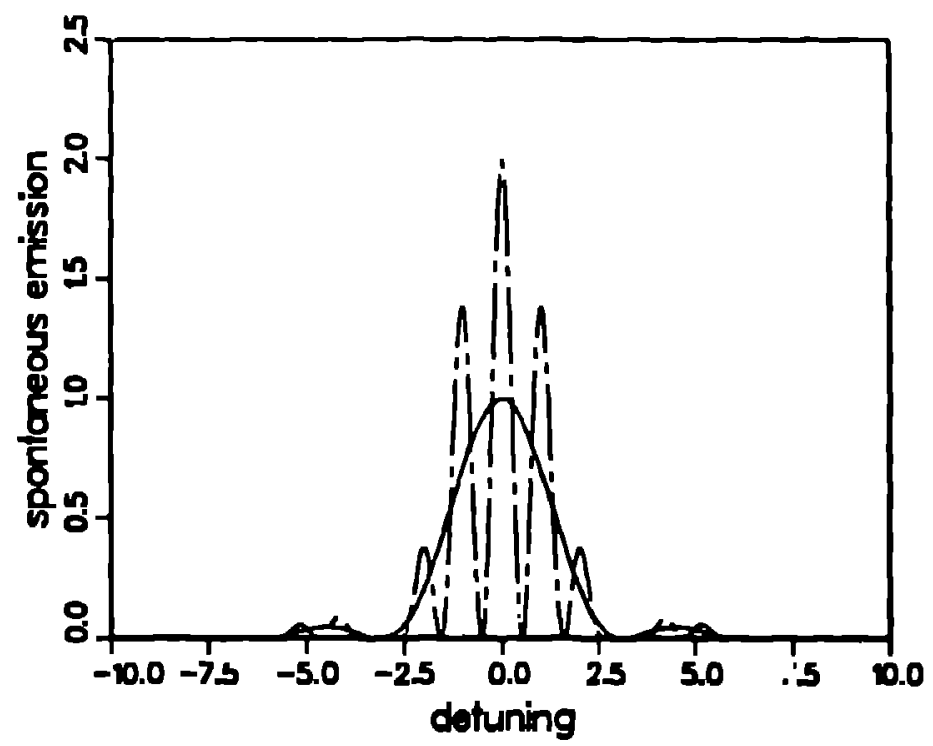

Figure 1. Characteristic lineshapes of the spontaneous emission from a single electron for both the single wiggler (solid line) and the optical klystron (dashed line) configuration. An equal number of wiggler periods was asumed for each configuration.

produced. Examples of the characteristic lineslıapes of the spontaneous emission for both the single wiggler and the optical klystron configuration are given in Figure 1.

To achicve harmonic output power above the spontaneous level one must achieve $c \leq \lambda_{r}$, where c represents the phase space area ( $x \times$ enultance) of the electron beam, (in at least some spatial section uf the electron beam) so that buncling can occur. For this case the coherent-spontaneous emission must be calculaled.

\section{COUERENT SPONTANEOUS EMISSION}

As previoissly mentioned, colierent-spontanzous emiasion arises due to the buncling of the electron beam. In an oscillator or amplifier this bunching is normally produced by the interaction of the electrons with radiatich at the fundamental frequency. Since the bunching is a non-linear proceas, small exial density components are produced at the harmonics of the fundaniental bunching wavelength. Coherent harmonic emission can then take place, where the strength of the radiation source is proportional to the amplitude of the density component at the harmonic of intereat, and the sum over transverse space of the distributed cources from each electron. The analytical form of the distributed electron cources has been previcusly derived ${ }^{10}$ and only the results of the formalism are of interest here.

The analy'sis of coherent radiation in FELs typically begina with the wave equation in the paraxial limit. The paraxial approximation is ideally suited for the analyuis of the tightly collimated coherent emisvion from FELs. Within the confincs of this approximation, the wave equation for the linearly polarized complex electric ficld from a plane polarized wiggler has the form ${ }^{12}$

$$
\left[2 i \int k_{1} \frac{d}{d z}+\frac{\theta^{2}}{\partial r_{\perp}^{2}}\right] E_{\perp}^{\prime}=-\frac{i \theta_{\pi} / k_{1}}{\lambda_{1} c} \int_{1}^{1+\lambda_{1}} d\left(J_{\perp}(z, y, \zeta) e^{-i /(t, c-\omega, 1]}\right.
$$

where $k_{0}=2 \pi / \lambda_{0}=w_{1} / c$ is the fundamentul optical wavenumber, $c$ is the opeed of light, $f$ is the harmionic number and $J_{\perp}$ is the transverse curscht given by

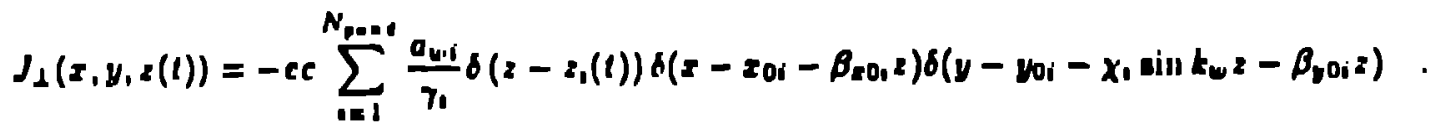


The sum over $i$ represrnts the contributions from all the electrons in a ponderomotive wavelrugth $\left(\lambda_{\text {pond }}^{-1}=\right.$ $\left.\lambda_{j}^{-1}+\lambda_{w}^{-1}\right)$. Here we have assumed a planc politrized wiggler magnetic field with period $\lambda_{w}$ and amplitude $\vec{B}=\dot{x} B_{w} \sin k_{w} z$. The electrous have charge, $q=-e$, and energy, $\gamma m c^{2}$, such that they wiggle in the

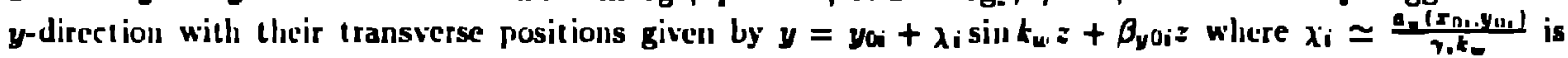
the oscillation amplitude of the $i^{\text {th }}$ electron and $a_{w}$ is the wiggler vector potential given in Eq.(5). The

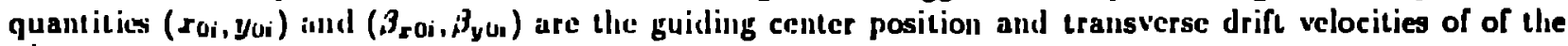
$i^{\text {th }}$ electron. 'To obtain a sourre function depend:'nt un the elsetron's transverse $y$ position alone, we average over a wiggler period yielding ${ }^{10}$

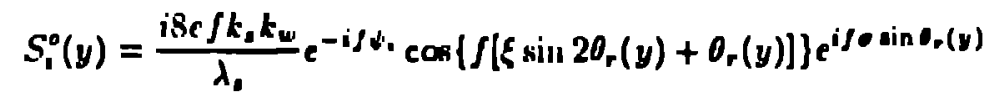

for the odd harmonies and

$$
S_{i}^{+}(y)=-\frac{8 c f k \cdot k_{w}}{\lambda_{1}} c^{-i / \psi_{1}} \sin \left\{\int\left[\xi \sin 2 \theta_{r}(y)+O_{r}(y)\right]\right\} e^{i f \cos \theta_{r}(y)}
$$

for the even harmonics where $\xi$ is the interaction strength parameter given in analogy with El.(4) by

$$
\varepsilon=\frac{a_{u}^{2}}{4\left(1+a_{u}^{2} / 2+\gamma^{3} \beta_{10_{i}}^{2}\right)}
$$

Bnd $\sigma$ is the ungular coupling factor defined

$$
\sigma=8 \varepsilon\left(\frac{\beta_{\text {yni }}}{a_{w i} / \gamma}\right)
$$

Note that the bracketed term in $\mathrm{E}_{\mathrm{q}}$ (12) is a ratio of the transverse driit velocity of an electron to its peak wiggle velocity. This ratio must be small for these results to be valid. Comparing Eq.(12) to Eq.(3) one sees thant the observition angle $\theta$ in the spont ancous emission expression has been replaced by the elect.ron misalignment allgle in the wiggler $\beta_{y 0 i} \simeq \beta_{y 0 i} / \beta_{1}$. The transverse source functions in Eqs.i(9) and (10) are a function of $O_{r}(y)$ give'n ly

$$
O_{r}(y)=\sin ^{-1}\left(\frac{y-y_{n i}}{\lambda_{i}}\right) \quad y_{0 i}-\lambda_{i} \leq y \leq y_{0 i}+x_{i}
$$

where we expliritly axj,ress the linits of $O_{r}(y)$, confining then to the transverse range of each clectron. The: source functions are complex quantities except when the electron is perfectly aligned with the wiggler axis $\left(0 \propto \beta_{y} \Rightarrow 0\right)$. The electron guiding center is at thr point $y=y_{0 i}$ and the width of the curve reflects the transverss wiggle range of the electron. P'lots of the cource func:ions including angular effects with $\sigma=\varepsilon=1 / 6$ are given in Figures $2 a, b$ for the fundamental and second harmonic. Since the source functions are complex, the the real and innginary' parts have heen plotled with dot-dash and dotted lines, respectively. For referenre, the solid line plots the suure function for $\sigma=0$. Nole that the real part of the source function is only slightely modified from its $\sigma=0$ value doxpite the large value of $\sigma$ assumed for these calculitions. As anen from Figgure: 2, misalignnent of an electron in the wiggler int roduces coupling to nodes with thes opposite trunsirerse symumet ry compared to the prirfectly aligned came.

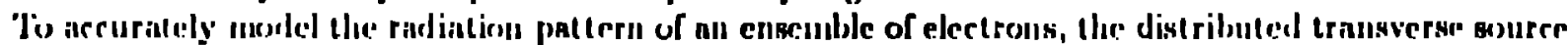

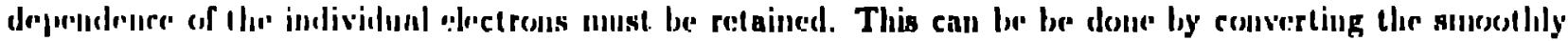

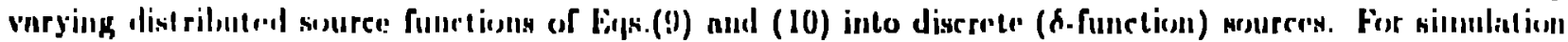

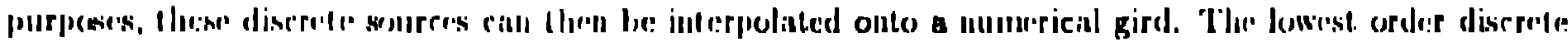

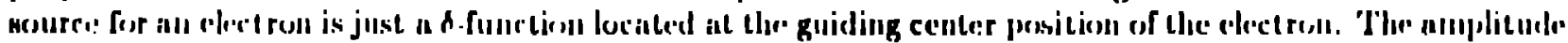

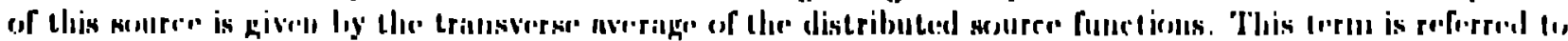

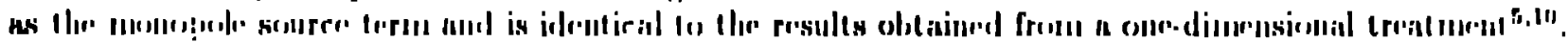




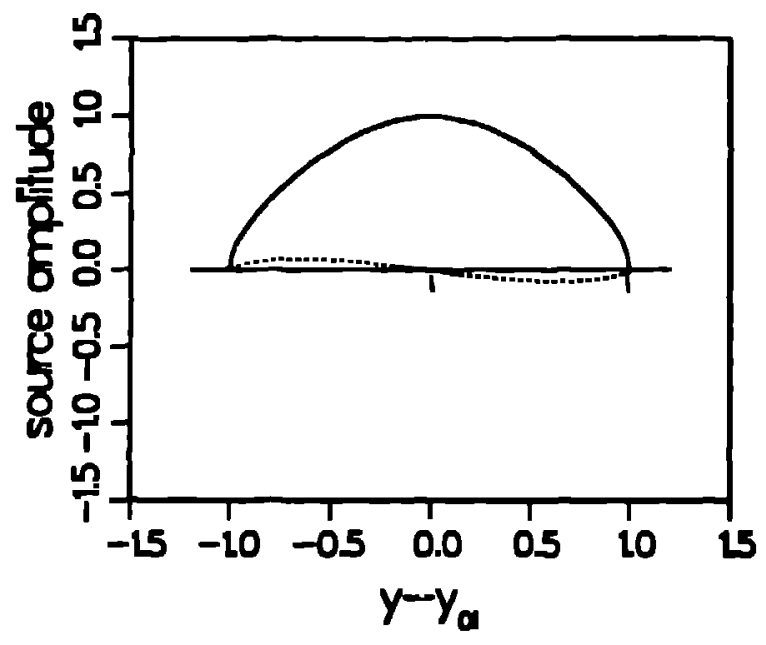

(a)

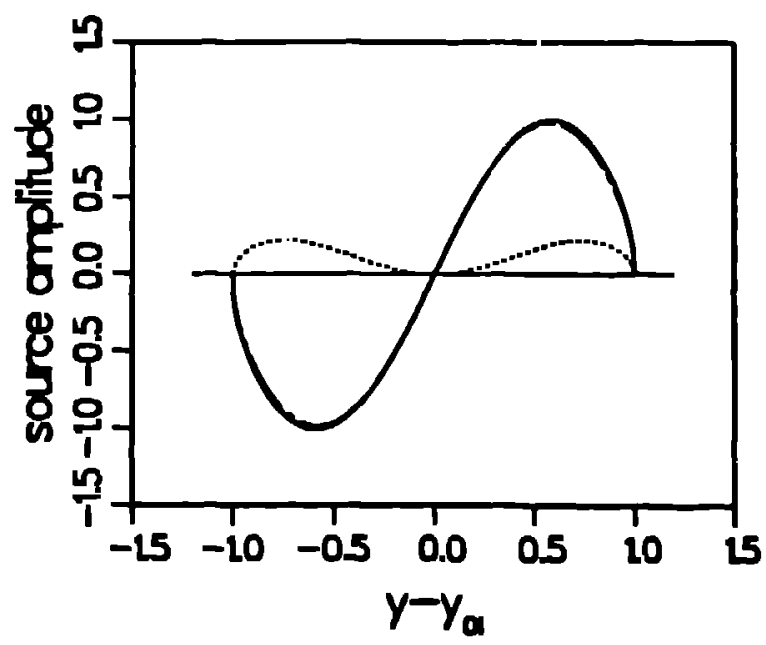

(b)

Figure 2. Plots of the distributed cource functions including angular effects with $\sigma=\varepsilon=1 / 0$ for (a) the fundamental and (b) sccond harmonic. The real and imaginary parts have been plotted with dot-dash and dotlcd lines, respectively. For reference, the soiid line plots the eource function for $\sigma=0$. Note that the large imaginary part introduees a source with opposile symmetry from the $\sigma=0$ reference case.

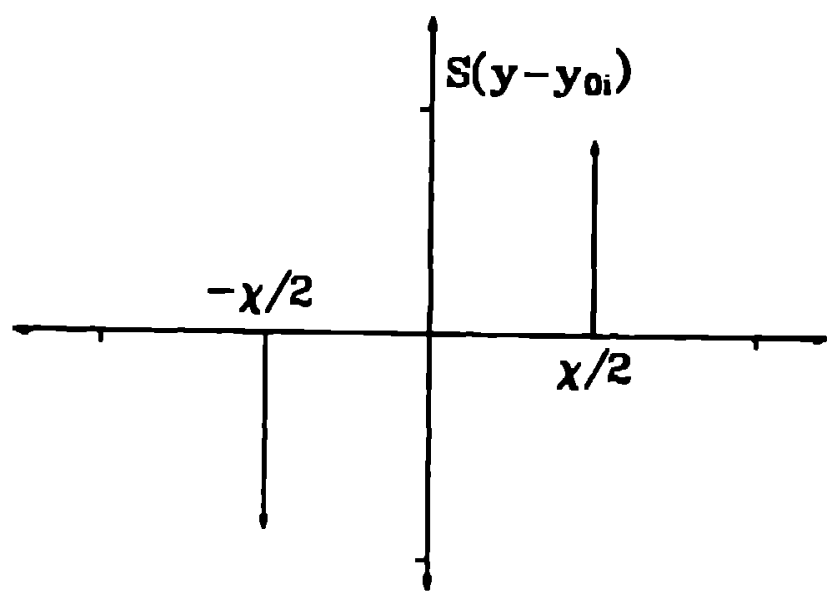

Figure 3. The discrete dipole source function for the second harmonic. The $\delta$-function cource have been positioned half the distance from the guiding center to the wiggle extrems.

As seen from Eq. (10) the lowest order amplitude for the even harmonica in the limit $\sigma \Rightarrow 0$ is zero due to the odd aymmetry of the sine term. To obtain a nonvanishing amplitude for the even harmonics in this limit we muat go to higher order. The next order discrete source for an electron would be a pair of 8 -funetiona in an odd configuration es aliown in Figure 3 . This term is referred to as the dipole source term. The amplitudes fur this cource and the third order discrete source (tripole) have been derived elnewhere ${ }^{10}$.

The wave equation including the three discrete cource term can now be writlen

$$
\left[2: y t_{1} \frac{d}{d z}+\frac{\partial^{2}}{\partial \dot{r}_{1}^{2}}\right] E_{\perp}^{\prime}=\sum_{j}^{1,2,3} S_{j}(y)
$$


where the three source terms on the right-liand side are given by:

- Mono-pole term

$$
S_{1}(y)=\left\langle\frac{i 1 \pi I f t, a_{u \cdot i}}{c} \kappa_{j}^{(1)}(\varepsilon, \sigma) \delta\left(y-y_{0 i}\right) \frac{e^{-i \delta \psi}}{\gamma}\right\rangle
$$

- Di-pole term

$$
S_{3}(y)=\left\langle\frac{4 \pi I f k_{,} a_{u i}}{c} \Lambda_{\rho}^{-(2)}(\xi, \sigma) \frac{1}{2}\left[\delta\left(y-y_{0 i}-x / 2\right)-\delta\left(y-y_{0 i}+\lambda / 2\right)\right] \frac{e^{-i \delta \psi}}{\gamma}\right\rangle
$$

- Tri-pole term

$$
\begin{aligned}
S_{3}(y)=- & \left\langle\frac{i 1 \pi I f k_{,} a_{u i}}{c}\left[\Lambda_{j}^{-(1)}(\xi, \sigma)-\Lambda_{J}^{(j)}(\xi, \sigma)\right]\right. \\
& \left.\times\left\{\delta\left(y-y_{0 i}\right)-\frac{1}{2}\left[\delta\left(y-y_{0 i}-\lambda / 2\right)+\delta\left(y-y_{0 i}+\lambda / 2\right)\right]\right\} \frac{e^{-i / \psi}}{\gamma}\right) .
\end{aligned}
$$

where

$$
\Lambda_{f}^{(m)}(\xi, \sigma)=(-1)^{\jmath} \sum_{n=-\infty}^{\infty} J_{n}(f \xi)\left[(-1)^{m} J_{2 n+J-m}\left(\int \sigma\right)-J_{2 n+f+m}(f \sigma)\right]
$$

Including higher order source terms in the sum in Eq.(13) will not significantly improve the accuracy of the calculation since tliese ternts ure eftectively averaged out by the electron cnscmble, assuming the transverse density profile is smocilily varying.

A three-dincusionnl simulation code inzorporating Eq.(13)-(17) has becu written. A typical result of the code is the odd symunetry of the even harmonic radiation patterns as sliown in Figure 4. Comparison of the simulation results with the power produced at the second through seventh harmonic of the Stanford Mark III FEL ${ }^{13}$ were initially conducted. The simulation results were in good agreement with the experimental measurenents for the first fuur harmonies as reported by Baniford and Deacon ${ }^{14}$. Closer comparisons of experiment and simulation will require nore accurate measurement of the electron beam location in the wiggler and resolution of the transverse harmonic intensity profiles on a micropulse time seale.

The gradient of the transverse wiggler field also contributes to the radiation at the harmonic frequencics. Ilowever, this coupling is small for conventionial FELs. The radiation into the even liarmonics caused by gratients in the wignher fiehd will be $\left(\lambda_{w} / \pi r_{e}\right)^{t}$ times weaker than the radiation caused by gradicuts: in the

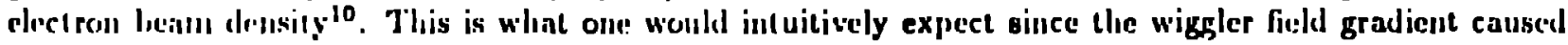
ly the large st:paration of the wigglo: magnets is much smaller than the tensity gradient inside the narrow eleceroull be:iant.

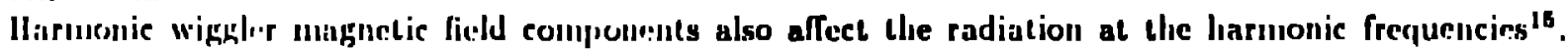

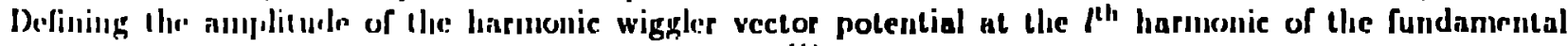

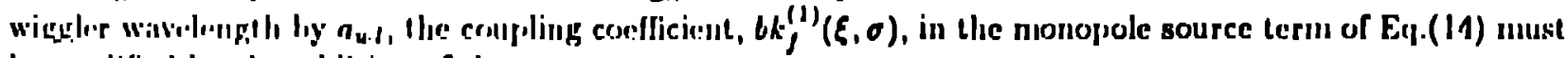
lire modified log the addition of the term

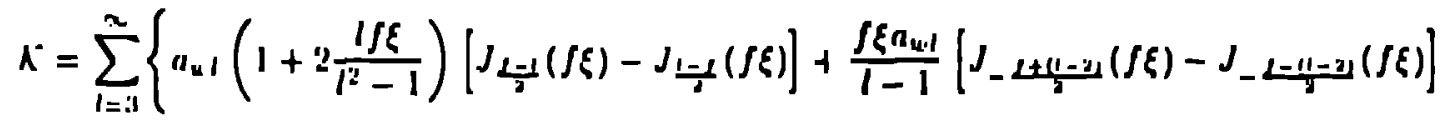

$$
\begin{aligned}
& \left.+\frac{\int \xi a_{u \cdot 1}}{l+1}\left[J_{-} \frac{2+u+21}{d}\left(\int \xi\right)-J_{-} \frac{2-u_{1+21}}{2}\left(\int \xi\right)\right]\right\}
\end{aligned}
$$

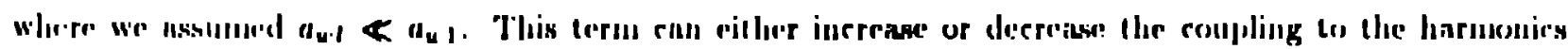

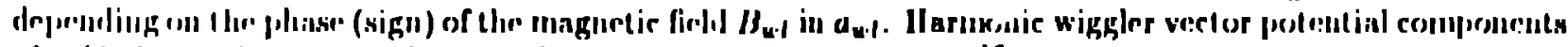

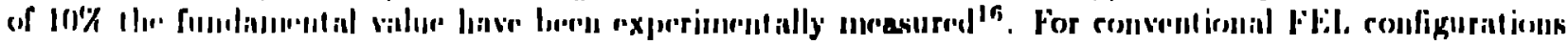

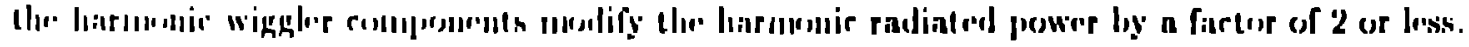




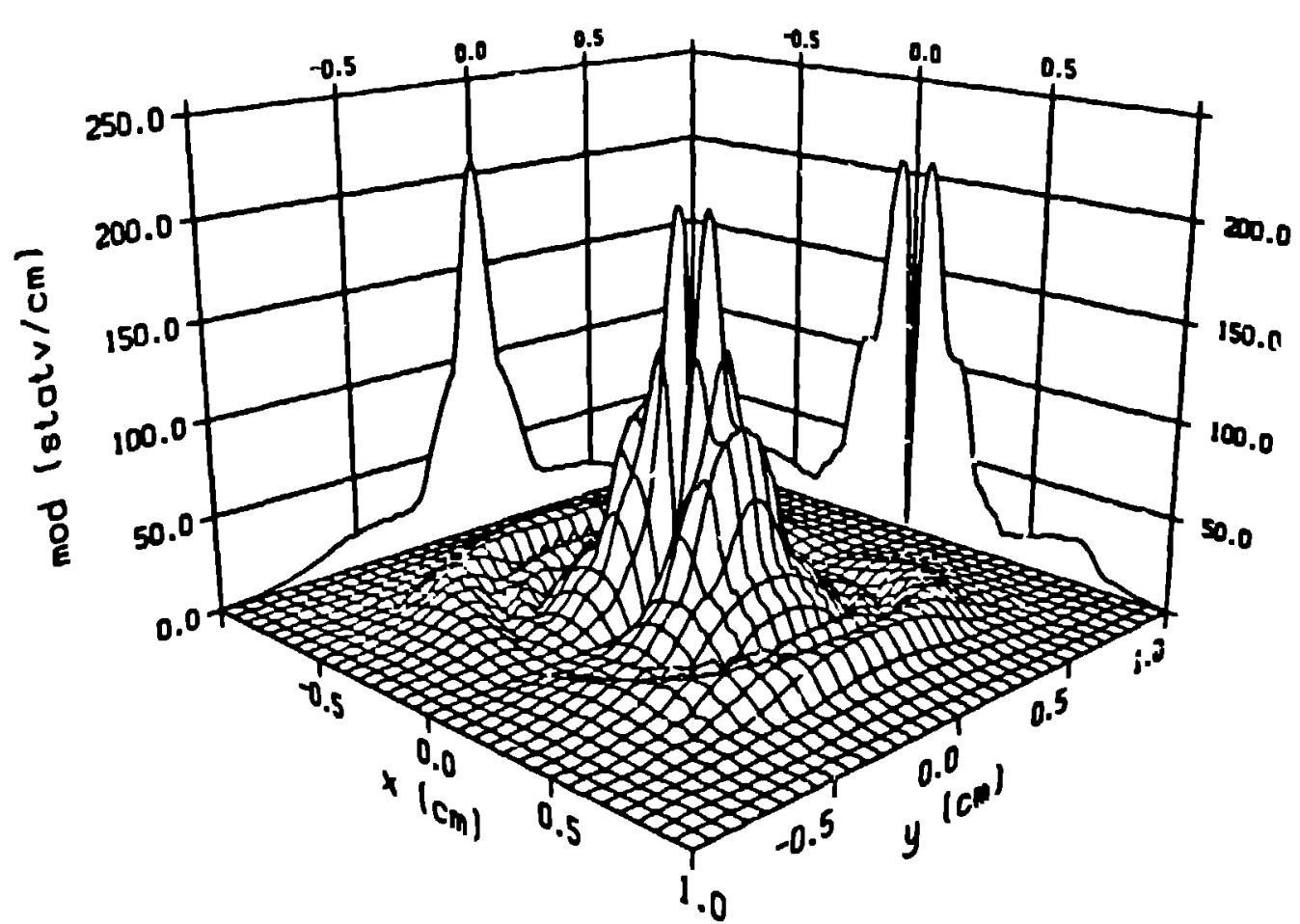

Figure 4. Plot of the magnitude of the electric field for the coherent-spontaneous emission at the second harmonic of a typical FEL amplifier. The negative amplitude lobe has been inverted for plotting purposes.

\section{CONCLUSIONS}

Formalisms now exist to calculate the spontaneous radiation of FELs al the harmonic frequencies in both the inculierent and coherent regimes. Simulations of harmonic emission for present FEL devices show good agrecment with experimental measurements. Modeling of the harmonics in more complicated FEL configurations that include tapered wigglers, prebunchers and optical klystrons will be studied in the future. Multi-pass interactions including harmonic lasing ${ }^{17,13}$ and interference effects of coherent-spontaneous emission $^{19}$ wili also be examined.

\section{ACLNOWLEDGNIENT}

The author wisher to thank C. Jim Eltiott and Brian D. Mc V'ey for their continuing theoretical and computational collaboration. Work performed under the auspices of the U. S. Department of Energy and supported by the U. S. Army Strategic Defense Command.

\section{REFERENCES}

1. MI. J. Schmilt and C. J. Ellioll, "Even-harmonic generation in free-electron lasers", Phys, Rev. A 34 pp4813-4850, 1986.

2. Even harmonic radiation is also produced by misaignment of the electron beam and the wiggler axis. llowever, this radiation is of much lower intensity.

3. W'. B. Colson, "The nonlinear wave equation for higher harmonies in free-electron lasers", IEEE J. Quantum Electron. QE-17 pp1417-1427 1981.

4. M. J. Schmitt, لlarmonic Production in Free-Eleclion hasers, Ph.D. Dissertation, UCLA 1987.

5. IW. B. Colson, G. Dattoli and F. Ciocci, "Angular-gain apectrum of free-electron lasers", Phys. Rev. A 31 pp828-842 1085.

6. Kwang-Je Kim, 'An analysis of self-amplified apontaneous emission", Nucl. Instr. and Meth. A250 
Pp'39G-103 1986.

7. B. C. Mel'ey, "Three-dimensional simulations of irec-electron laser physies" Nuel. Instr. and Meth. A250 ppi-19-455 1980.

B. M. J. Schmitt and C. J. Elliot,, "Theory of ha:monic radiation using a single-electron source model", Proceedings of the Eleventh International Conference on Free Electron Lasers, August 28 through September 1, 1989, held in Naples, FL, to be published.

9. J. D. Jackson, Clasaical Electrodjnamirs, p671, Wiley, New York, 1975.

10. M. J. Sclinitt and C. J. Ellictt, "Gencralized derivation of free-electron laser harmonic radiation from plane-polarized wigglers", Phys. Rev. A, accepled for publication.

11. Pascal Elleaume, "Theory of the optical klystron", Nucl. Instr. and Meth. A250 pp220227 1980.

12. 'I'he paraxial wave equation invokes the slowly varying envelope approximation as discussed in: $M$. Sargent, M. O. Scully, and IV. E. Lamb, Laser Physics, p100 Addison Wesley, Reading, 1974. The analogous expression for a llcrmite-gaussian mode set is derived in reference [1].

13. S. V. Benson, cl. al., "The Stanford Mark III infrared free electron laser", Nucl. Instr. and Meth. A 250 pp39-43 1986.

14. D. J. Bamford and D. A. G. Deacon, "Measurement of the coherent harmonic emission Irom a freeelectron laser oscillator", Plyys. Rev. Lett. 62 Number 10, ppl106-1109, 1089.

15. M. J. Schnitt and C. J. Elliott, "The effects of harranic wiggler field components on free-electron laser operation", IEEE J. Quantum Electron. QE-23 155:-:557 1987.

16. li. Ialbach, "Permanent magnet undulators", Journal de Physique, Colloque Cl, supplément au $n^{\circ} 2$ Tounc 44, pp211-216, 1083.

17 S. V. Benson and J. M. J. Madey, "Demonstration of harmonic lasing in a free-electron laser", Pliys. IRev. A $39 \mathrm{pl} 1570-15811089$.

18. R. W". IVarren, et. al., "Lasing on the third harmonic", Procecdings of the Eleventh luternational Conference on Free Elertron Lasers, August 28 through September 1, 1909, held in Naplns, FL, to be published.

19. 13. A. Newnanı, et, al., "Ilirmonie generation-strength and mode shape", Procecdings of the Eleventl, International Conference on Frec Electron Lasers, August 28 througl, Septem'ser 1, 1989, he!d in Naples, FL, to be publislied. 